\section{Original Article}

\section{OPEN ACCESS}

*Correspondence

Itodo Cornelius Elachi. Department of Surgery, Benue

State University, Makurdi

Tel: +2348036279212 Email: elachitodo@gmail.com

Specialty section: This article was submitted to Surgery, a section of JRBCS

\title{
Adequacy of Undergraduate Orthopaedic Education in Makurdi, North central Nigeria
}

Elachi IC, Yongu WT, Kortor JN.

Department of Surgery, Benue State University, Makurdi Nigeria.

\begin{abstract}
A large number of patients seek help for musculoskeletal conditions. Students and doctors have been noted to have a poor cognitive mastery of the subject area. This study aims to determine the adequacy of orthopedic learning of final year medical students. Freedman and Bernstein's validated basic cognitive examination was administered to final year medical students who had completed their orthopaedic surgery course work and clinical rotations. Overall scores and responses to the individual questions were analyzed using SPSS. The recommended passing score of 73.1 per cent was employed. Forty undergraduate medical students took part in the study. None of the students attained the passing score of $\geq 73.1 \%$. The mean score was $21.2 \%$. The students performed best in general orthopaedics with a mean score of $11.4 \%$. They scored $5.3 \%$ and $4.6 \%$ in anatomy and trauma respectively. The final year undergraduate students had poor knowledge of orthopaedics. Considering the huge burden of musculoskeletal complaints, further studies are needed to assess interventions that will lead to curriculum improvement in the school.
\end{abstract}

Keywords:, Adequacy, Medical education, Orthopaedic, Undergraduate

\section{INTRODUCTION}

Received: 21 June 2021

Accepted: 9 July 2021 Published: 15 July 202

$\mathrm{M}$ usculoskeletal disorders are common and are among the leading reasons patients seek medical consultation. ${ }^{1}$ They represent a large proportion of patients seen in health facilities constituting about $20 \%$ of presentations to emergency Citation: rooms and 15 to $30 \%$ of primary care visits in the United States of America. ${ }^{2,3}$ Most Elachi IC, Yongu WT, Kortor JN. Adequacy of Undergraduate Orthopaedic Education in Makurdi, North central Nigeria. $J$ Res Bas Clin Sci 2(1):43-48 DOI.10.46912/jrbcs. 97

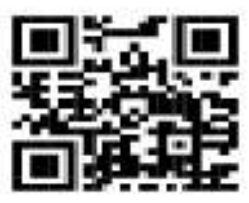

http://jrbc.org care is offered by doctors whose major musculoskeletal understanding is obtained from undergraduate experience.

Freedman and Bernstein ${ }^{4}$ in 1998, studied some medical school graduates on basic topics in musculoskeletal medicine to assess the adequacy of their preparation in the area. A basic competency examination in musculoskeletal medicine was developed and validated. The examination was administered to eighty-five residents who were in their first postgraduate year. Eighty-two (82) per cent of the medical school graduates failed the validated musculoskeletal competency examination which led the authors to conclude that medical school preparation in musculoskeletal medicine was inadequate. Similar studies afterwards have demonstrated deficiencies in the 
adequacy of musculoskeletal medicine at different stages of the medical educational process. ${ }^{5-8}$ Others have shown medical students do not feel adequately prepared in musculoskeletal medicine and lack both clinical confidence and cognitive mastery in the field. $9,10,11$

Musculoskeletal medicine involves orthopaedic surgery, physical therapy, rheumatology and radiology. In our institution, the various components are taught under orthopaedic surgery except for radiology. The curriculum consists of formal lectures, small group teaching seminars, bedside teaching sessions and participation in clinical activities. Students' clinical postings involve rotations through the orthopaedic units. However, there are no mandatory orthopaedic rotations.

Due to the high prevalence of orthopaedic disorders, it is pertinent that medical students are well-grounded to eventually provide adequate patient care as doctors. This study aims to determine the adequacy of orthopedic learning of final year undergraduate students.

\section{MATERIALS AND METHODS}

The Freedman and Bernstein's validated basic cognitive examination ${ }^{4}$, consisting of twenty-five short answer questions, was administered to final year medical students of Benue State University who had completed their orthopaedic and trauma surgery course work and clinical rotations. Approval for the study was obtained from the university hospital Health Research and Ethics Committee. Students who were not interested in participating in the study were excluded. Informed consent was obtained from all the participants. No prior knowledge of this examination was provided to the students. No time limit was given for completion of the examination. Answer sheets were collected promptly and scored anonymously by the authors of the study. The questions were separated into general orthopaedics, trauma and anatomy groups.
Each question was worth one mark, but partial credit was given for questions with multiple answers. The raw scores were multiplied by four to obtain percentage scores. Overall scores and responses to the individual questions were analyzed. The recommended passing score of 73.1 per cent as suggested by Freedman and Bernstein was employed in the study.

Data were analyzed using the software IBM SPSS Statistics for Windows, version 21.0 (Armonk, NY, USA: IBM Corp). Descriptive statistics were employed to display single-variable quantities using means and standard deviations for continuous variables or proportions for categorical variables unless otherwise stated.

\section{RESULTS}

Forty undergraduate medical students out of a class of 43 took part in the study. None of the students attained the passing score of $\geq 73.1 \%$. The mean score was $21.2 \%$. These ranged from $0.0 \%$ for the questions on congenital hip dislocation (Question No. 1) and testing the motor function of the median nerve in the hand (Question No. 12) to $80.0 \%$ for those on carpal tunnel syndrome (Question No. 10) sources of cancer metastasis (Question 17). The mean scores for each question are shown in Table 1. The students performed best in general orthopaedics with a mean score of $11.4 \%$. They scored $5.3 \%$ and $4.6 \%$ in anatomy and trauma respectively. 
Table 1: Mean scores obtained by students for each question in the study.

\begin{tabular}{lll}
\hline Mean Question & Answer & Score \% \\
\hline $\begin{array}{l}\text { 1. What common problem must all newborns be } \\
\text { examined for? }\end{array}$ & $\begin{array}{l}\text { Congenital dislocation of the hip (CDH, dislocation; } \\
\text { subluxation also accepted): 1 point }\end{array}$ & 0.0 \\
$\begin{array}{l}\text { 2. What is compartment syndrome? } \\
\begin{array}{l}\text { 3. Acute septic arthritis of the knee may be } \\
\text { differentiated from inflammatory arthritis by which }\end{array}\end{array}$ & $\begin{array}{l}\text { Ancreased pressure in a closed fascial space: 1 point } \\
\text { laboratory test? }\end{array}$ & 50.0 \\
$\begin{array}{l}\text { 4. A patient dislocat culture): 1 point } \\
\text { Sis knee in a car accident. }\end{array}$ & Must mention popliteal artery: 1 point & 31.3 \\
\hline
\end{tabular}

What structure/s is/are at risk for injury and therefore must be evaluated?

5. A patient punches his companion in the face and sustains a fracture of the 5th metacarpal and a 3-mm break in skin over the fracture. What is the correct treatment and why?

6. A patient comes to the office complaining of low back pain that wakes him from sleep. What two diagnoses are you concerned about?

7. How is compartment syndrome treated?

8. A patient lands on his hand and is tender to palpation in the snuff box (the space between the thumb extensor and the adductor tendons). Initial radiographs do not show a fracture. What diagnosis must be considered?

9. A 25 -year-old male is involved in a motor vehicle accident. His left limb is in a position of flexion at the hip and knee with internal rotation and adduction at the hip. What is the most likely diagnosis?

10. What nerve is compressed in carpal tunnel syndrome?

11. A patient has a disc herniation pressing the 5 th lumbar nerve root. How is the motor function of the fifth lumbar root tested?

12. How is the motor function of the median nerve tested in the hand?

13. A 12 -year-old boy severely twists his ankle. Radiographs show only soft tissue swelling. He is tender at the distal aspect of the fibula. What are the two possible diagnoses?

14. A patient presents with new onset low back pain. Under what conditions are plain radiographs indicated? Please name five (example: history of trauma)

15. A patient has a displaced fracture near the fibular neck. What structure is at risk for injury?

16. A 20 -year-old injures his knee while playing football. You see him in the same day and he has a knee effusion. An aspiration shows frank blood.

What are the three common diagnoses?

17. What are the five common sources of cancer metastasis to the bone?

Dorsiflexion of the great toe (toe extensors also accepted): 1 point

Any median nerve function (Metacarpophalangeal finger flexion; thumb opposition, flexion or abduction): 1 point

Ligament sprain and Salter-Harris 1 fracture (sprain, fracture also accepted): $1 / 2$ point each

Age > 50 years; neurological deficit; bowel or bladder changes; history of cancer; drug use or steroid use; systemic symptoms (night pain, fever); pediatric population: $1 / 2$ point each, full credit for 2 correct responses

Common peroneal nerve (peroneal nerve also accepted): 1 point

Ligament tear, fracture, peripheral meniscal tear (capsular tear, patellar dislocation also accepted): $1 / 2$ point each, full credit for 2 correct responses

Breast, prostate, lung, kidney, thyroid: $1 / 4$ point each, full credit for four correct responses 
Table 1 Continued: Mean scores obtained by students for each question in the study.

\begin{tabular}{|c|c|c|}
\hline Mean Question & Answer & Score \% \\
\hline $\begin{array}{l}\text { 18. Name two differences between rheumatoid } \\
\text { arthritis and osteoarthritis? }\end{array}$ & $\begin{array}{l}\text { Any two correct statements (e.g., inflammatory vs. } \\
\text { degenerative, proximal vs. distal interphalangeal joint, etc.): } \\
1 / 2 \text { point each }\end{array}$ & 1.3 \\
\hline $\begin{array}{l}\text { 19. What malignancy may be present in bone yet } \\
\text { typically is not detected on the bone scan? }\end{array}$ & $\begin{array}{l}\text { Myeloma (full credit for haematological malignancies- } \\
\text { leukaemia, lymphoma): } 1 \text { point }\end{array}$ & 7.5 \\
\hline $\begin{array}{l}\text { 20. What is the function of the normal anterior } \\
\text { cruciate ligament of the knee? }\end{array}$ & $\begin{array}{l}\text { To prevent anterior translation of the tibia on the femur: } 1 \\
\text { point }\end{array}$ & 1.3 \\
\hline $\begin{array}{l}\text { 21. What is the difference between osteoporosis and } \\
\text { osteomalacia? }\end{array}$ & $\begin{array}{l}\text { Osteoporosis - decreased bone density; osteomalacia - } \\
\text { decreased bone mineralization (any true statement about } \\
\text { epidemiology, pathophysiology, e.g., estrogen vs. vitamin } \\
\text { D also accepted): } 1 \text { point }\end{array}$ & 7.5 \\
\hline $\begin{array}{l}\text { 22. In elderly patients, displaced fractures of the neck } \\
\text { of femur are typically treated by joint replacement, } \\
\text { whereas fractures of the trochanter are treated by } \\
\text { plate and screws. Why? }\end{array}$ & $\begin{array}{l}\text { Blood supply to femoral head (avascular necrosis, nonunion } \\
\text { also accepted): } 1 \text { point }\end{array}$ & 16.3 \\
\hline $\begin{array}{l}\text { 23. What muscle/s is/are involved in lateral } \\
\text { epicondylitis? }\end{array}$ & $\begin{array}{l}\text { Wrist extensors (full credit for any wrist extensor - } \\
\text { extensor carpi radialis brevis, extensor carpi radialis longus, } \\
\text { extensor digitorum communis): } 1 \text { point }\end{array}$ & 0.0 \\
\hline $\begin{array}{l}\text { 24. Rupture of the biceps at the elbow results in } \\
\text { weakness of both elbow flexion and } \ldots \ldots \ldots \ldots \ldots \ldots \text { ? }\end{array}$ & Supination: 1 point & 10.0 \\
\hline $\begin{array}{l}\text { 25. What muscle(s) control(s) external rotation of the } \\
\text { humerus with the arm by the side? }\end{array}$ & Infraspinatus or teres minor accepted (full credit): 1 point & 7.5 \\
\hline
\end{tabular}

\section{DISCUSSION}

It is important to ensure that all graduating doctors possess the necessary knowledge and skillset to diagnose and treat musculoskeletal disorders. Deficiencies in musculoskeletal education at different levels of the medical education process were noted decades ago leading to suggestions of reforms. Evaluating the adequacy of musculoskeletal learning at undergraduate level will help as a guide in curriculum review to improve knowledge and skill acquisition of doctors.

In this study, we evaluated the knowledge in musculoskeletal medicine of final year medical students who had completed their rotations using the Freedman and Bernstein questionnaire. None of the students attained the pass mark of $73.1 \%$. Poor performances following administration of the Freedman and Bernstein's validated cognitive musculoskeletal examination to medical students have been reported in previous studies. ${ }^{5,67}$ Following Freedman and Bernstein's landmark study that demonstrated the inadequacy of musculoskeletal knowledge among medical school graduates, different schools have reformed their undergraduate musculoskeletal medicine curricula. However, students and doctors at different levels continue to show poor cognitive knowledge in musculoskeletal education. Increasing musculoskeletal lecture time has been considered as a modality to improve musculoskeletal knowledge among medical students. Weiss et al. administered a validated musculoskeletal cognitive examination to four hundred and five medical students before and after a new module to determine the impact of the module on their competency. ${ }^{13}$ While the mean examination score was below the recommended 
passing score, the scores were significantly higher for the pre-module group than the post-module group despite the latter having more lecture and laboratory time. This led the authors to suggest that increasing musculoskeletal lecture time may not improve medical students' knowledge of musculoskeletal medicine. A similar finding was obtained by Day et al..$^{14}$

Routine clinical clerkships do not automatically provide a conducive learning environment for medical students. ${ }^{15}$ This may be because many of such clinical teaching activities are passive, low-level cognitive actions. ${ }^{16}$ Studies on structured educational interventions have been carried out to investigate timedependent effects of assisted learning in addition to a standard musculoskeletal curriculum. Perrig et al. ${ }^{16}$ conducted a controlled study of 48 medical students studying musculoskeletal physical examination. All the students underwent the regular clerkship programme. The intervention group received 6 lessons each of 1 hour-long interactive small group examination skills teaching in addition to the regular clinical clerkship. It was noted that the students in the intervention group not only improved their skills immediately after the teaching but also maintained these acquired skills several months afterwards. In contrast, the controls, who only carried out regular clerkship activities, such as hospital placements, could not improve their examination skills. Improvement in musculoskeletal cognition and or examination skills have been obtained by other studies ${ }^{17,18,19}$ Interactive small-group musculoskeletal teachings with a hands-on examination of real patients, with detailed feedback involving specialists, peers and patients may be incorporated into the curriculum to improve cognition and competence. Equally, students who had taken elective postings in musculoskeletal medicine have been noted to do better on the Freedman and Bernstein's validated cognitive musculoskeletal examination; which has been attributed to exposure to and interest. ${ }^{4,7,13}$

\section{CONCLUSION}

The final year undergraduate students had poor knowledge of orthopaedics. Cognitive mastery was best in general orthopaedics but worst in trauma surgery.

\section{Recommendation}

Considering the huge burden of musculoskeletal complaints, further studies are needed to assess interventions that will lead to curriculum improvement in the school

\section{Limitations}

Freedman and Bernstein's questionnaire does not include common musculoskeletal conditions within the study area like chronic osteomyelitis, tuberculous spondylitis, talipes equinovarus and traditional bone setters' limb gangrene. The students had trauma and orthopaedic surgery rotations at different times. This may result in an inability of some students to recall content well and maybe a limitation to attaining high scores. These factors may have acted as limitation factors and contributed to the poor scores obtained.

\section{REFERENCES}

1. Day, Charles S. MD; Yeh, Albert C.; Franko, Orrin; Ramirez, Miguel; Krupat, Edward $\mathrm{PhD}$ Musculoskeletal Medicine: An Assessment of the Attitudes and Knowledge of Medical Students at Harvard Medical School, Academic Medicine: May 2007 - Volume 82 - Issue 5 - p 452-457

2. Al-Nammari SS, Pengas I, Asopa V, Jawad A, Rafferty M, Ramachandran M. The inadequacy of musculoskeletal knowledge in graduating medical students in the United Kingdom. J Bone Joint Surg Am. 2015; 97(7):e36

3. Hussain, W, Hussain, H, Manning, DW. Student opinions on orthopedic residency selection, education, and work hours. American Journal of 
Orthopaedics 2013; 42(8), 358-361.

4. Freedman KB, Bernstein J. The adequacy of medical school education in musculoskeletal medicine. J Bone Joint Surg Am. 1998; 80:14217.

5. Tamrakar R, Gyawali B, Bhatta TR et al. Adequacy of Undergraduate Orthopedic Training at a Nepalese Medical Academy. MJSBH 2016; 15: 13-17.

6. Menon J, Patro DK. Undergraduate orthopedic education: Is it adequate? Indian J Orthop. 2009;43(1):82-86.

7. Matzkin E, Smith EL, Freccero D, Richardson $\mathrm{AB}$. Adequacy of education in musculoskeletal medicine. J Bone Joint Surg Am. 2005; 87:3104.

8. Matheny JM, Brinker MR, Elliott MN, Blake R, Rowane MP. Confidence of graduating family practice residents in their management of musculoskeletal conditions. Am J Orthop. 2000;29:945-52

9. Elachi IC, Kotor JN, Yongu WT, Efu ME. The perceptions and attitudes of medical students towards orthopaedic and trauma surgery teaching in Makurdi, Nigeria. Niger J Orthop Trauma 2020; 19:65-8.

10. Analyzing clinical case distributions to improve an emergency medicine clerkship. De Lorenzo RA, Mayer D, Geehr EC. Ann Emerg Med. 1990; 19(7):746-51.

11. Day CS, Yeh AC. Evidence of educational inadequacies in region-specific musculoskeletal medicine. Clin Orthop Relat Res. 2008;466(10):2542-2547. doi:10.1007/s11999008-0379-0

12. Munga MA, Maestad O. Measuring inequalities in the distribution of health workers: The case of Tanzania. Hum Resour Health. 2009;7:4.

13. Queally JM, Kiely PD, Shelly MJ, O'Daly BJ, O'Byrne JM, Masterson EL. Deficiencies in the education of musculoskeletal medicine in
Ireland. Ir J Med Sci. 2008; 177:99-105.

14. Weiss K, Curry E, Matzkin E. Assessment of medical school musculoskeletal education. Am J Orthop (Belle Mead NJ). 2015; 44(3):E64-7. PMID: 25750952.

15. Day CS, Ahn CS, Yeh AC, Tabrizi S. Early assessment of a new integrated preclinical musculoskeletal curriculum at a medical school. Am J Orthop. 2011; 40(1):14-18.

16. Remmen R, Denekens J, Scherpbier A, Hermann I, van der Vleuten C, Royen PV et al. An evaluation study of the didactic quality of clerkships. Med Educ. 2000; 34(6):460-4.

17. Perrig M, Berendonk C, Rogausch A, Beyeler C. Sustained impact of a short small group course with systematic feedback in addition to regular clinical clerkship activities on musculoskeletal examination skills--a controlled study. BMC Med Educ. 2016; 16:35.

18. Lawry GV 2nd, Schuldt SS, Kreiter CD, Densen $\mathrm{P}$, Albanese MA. Teaching a screening musculoskeletal examination: a randomized, controlled trial of different instructional methods. Acad Med. 1999 Feb;74(2):199-201

19. Queally JM, Cummins F, Brennan SA, Shelly MJ, O'Byrne JM. Assessment of a new undergraduate module in musculoskeletal medicine. Journal of Bone and Joint Surgery American 2001;93(3):e9-16. 